\title{
Infection of Olive Trees by Heterodera mediterranea in Orchards in Southern Spain
}

P. Castillo, Research Nematologist, Instituto de Agricultura Sostenible, Consejo Superior de Investigaciones Cientificas (IAS-CSIC), Apdo. 4084, 14080-Córdoba, Spain; N. Vovlas, Research Nematologist, Istituto di Nematologia Agraria, Consiglio Nazionale delle Ricerche, Via G. Amendola 165/a, 70126-Bari, Italy; A. I. Nico, Graduate Student, IAS-CSIC; and R. M. Jiménez-Díaz, Professor, IAS-CSIC and Departamento de Agronomía, Universidad de Córdoba, Apdo. 3048, 14080 Córdoba, Spain

\begin{abstract}
Castillo, P., Vovlas, N., Nico, A. I., and Jiménez-Díaz, R. M. 1999. Infection of olive trees by Heterodera mediterranea in orchards in southern Spain. Plant Dis. 83:710-713.

High infection rates of olive feeder roots and soil infestation by the cyst-forming nematode Heterodera mediterranea were found in commercial olive orchards cv. Manzanilla established in sandy soils at two localities of Sevilla Province of Andalucía, southern Spain. No disease symptoms were noted on the aboveground plant parts, but slightly distorted feeder roots and necrotic areas were observed near the infection points. Sedentary juvenile stages and adult females showed a semi-endoparasitic feeding habit. Histopathological studies of infected olive roots showed a disease response typical of cyst nematode infection of susceptible hosts. Nematode feeding induced syncytial formation involving cellular alterations in the cortex, endodermis, pericycle, and vascular parenchyma tissues in both cortical and endodermal root cells.
\end{abstract}

Additional keywords: cyst nematodes, host-parasite interaction

Injury to agricultural crops by cyst nematodes is probably second in importance to injury by root-knot nematodes worldwide. A number of cyst nematodes are highly virulent on specific major crops including grains, root crops, most legumes, and some woody plants (1). Currently, nine cyst-forming nematode species belonging to the genera Heterodera, Globodera, and Sarisodera are reported as parasites of woody plants $(5-7,10,14,18,19)$.

Olive (Olea europaea), an evergreen tree native to western Asia, is grown in the Mediterranean Basin, the subtropical regions of Australia, southern Africa, and North and South America. Some 750 million trees are grown in approximately 8.5 million ha, of which about $97 \%$ are in Mediterranean countries (3). The leading olive-producing countries in the Mediterranean Basin are Spain, Italy, and Greece. Several plant-parasitic nematodes have been found associated with olive trees wherever they are grown, including Meloidogyne spp., Pratylenchus spp., Helicoty-

Corresponding author: P. Castillo

E-mail: ag1cascp@lucano.uco.es

Accepted for publication 5 May 1999.

Publication no. D-1999-0621-01R

(C) 1999 The American Phytopathological Society lenchus spp., and Criconemella xenoplax (11). No cyst-forming nematodes have been reported to parasitize olive roots under natural conditions, although olive was included in the narrow host range of Heterodera mediterranea based on results from artificial inoculations (17).

Nematode surveys taken in September 1997 and May 1998 of 20 established (more than 30-year-old) commercial olive orchards in Sevilla province of Andalucía, southern Spain, revealed high infection rates of feeder roots by $H$. mediterranea in two sandy soils. This is the first record of natural infections of olive by a cyst-forming nematode. This paper reports on aspects of the diagnosis, life cycle, and histopathology of this nematode on olive roots.

\section{MATERIALS AND METHODS}

Nematode diagnosis. Samples of olive feeder roots (cv. Manzanilla), together with rhizosphere and bulk soil, were taken with a shovel from the upper $20 \mathrm{~cm}$ of soil from each of two drip-irrigated olive orchards at Utrera and Arahal (Sevilla province) in southern Spain. Cysts and females were collected directly from the sampled roots, while second-stage juveniles, mature cysts, and males were extracted from soil by flotation (4). For morphological and diagnostic studies, specimens were glycerine infiltrated and preserved by conventional methods (13), and cysts were fixed and mounted in lactophenol.

Histopathology. Segments of infected olive roots were gently rinsed with water, fixed in a formaldehyde chromoacetic solution for $48 \mathrm{~h}$, dehydrated in a tertiary butyl alcohol series (40-70-85-90-100\%), and embedded in $58^{\circ} \mathrm{C}$ melting point paraffin for histopathological observations. Embedded tissues were sectioned with a rotary microtome. Sections 10 to $12 \mu \mathrm{m}$ thick were mounted on glass slides, stained with safranin and fast-green, mounted permanently in dammax xylene, examined microscopically, and photographed (9).

\section{RESULTS AND DISCUSSION}

Nematode diagnosis. Detailed morphometric observations based on secondstage juveniles, male body length, stylet length, adult female and cyst shape, and vulval cone features (Fig. 1) agreed well with those that characterize the type population of $H$. mediterranea Vovlas et al. (18).

No disease symptoms were observed on aboveground plant parts even though a heavy soil infestation occurred (Fig. 1A). Slightly distorted feeder roots and necrotic areas were observed near the infection points (Fig. 1C to G). Nematode population levels in soil ranged from 465 to 1,336 eggs and second-stage juveniles, and 46 to 124 mature cysts per $250 \mathrm{ml}$ of soil. Cysts contained an average of 346 eggs each. A large, gelatinous egg sac matrix was present, containing a limited number of eggs (ranging from 0 to 32) (Fig. 1H). Second-, third-, and fourth-stage juveniles and adult females, many of them covered by a white subcrystalline layer (Fig. 1C to G), were observed partially embedded into the cortex of roots. The semi-endoparasitic behavior of juveniles of $H$. mediterranea observed in olive roots is coincident with that found by Vovlas and Inserra (17) in pistachio. In general, juveniles of cyst nematodes invade host roots and migrate intracellularly through the cortex until they settle permanently and establish their feeding sites (8). Our observations in olive roots confirm the semi-endoparasitic habit 

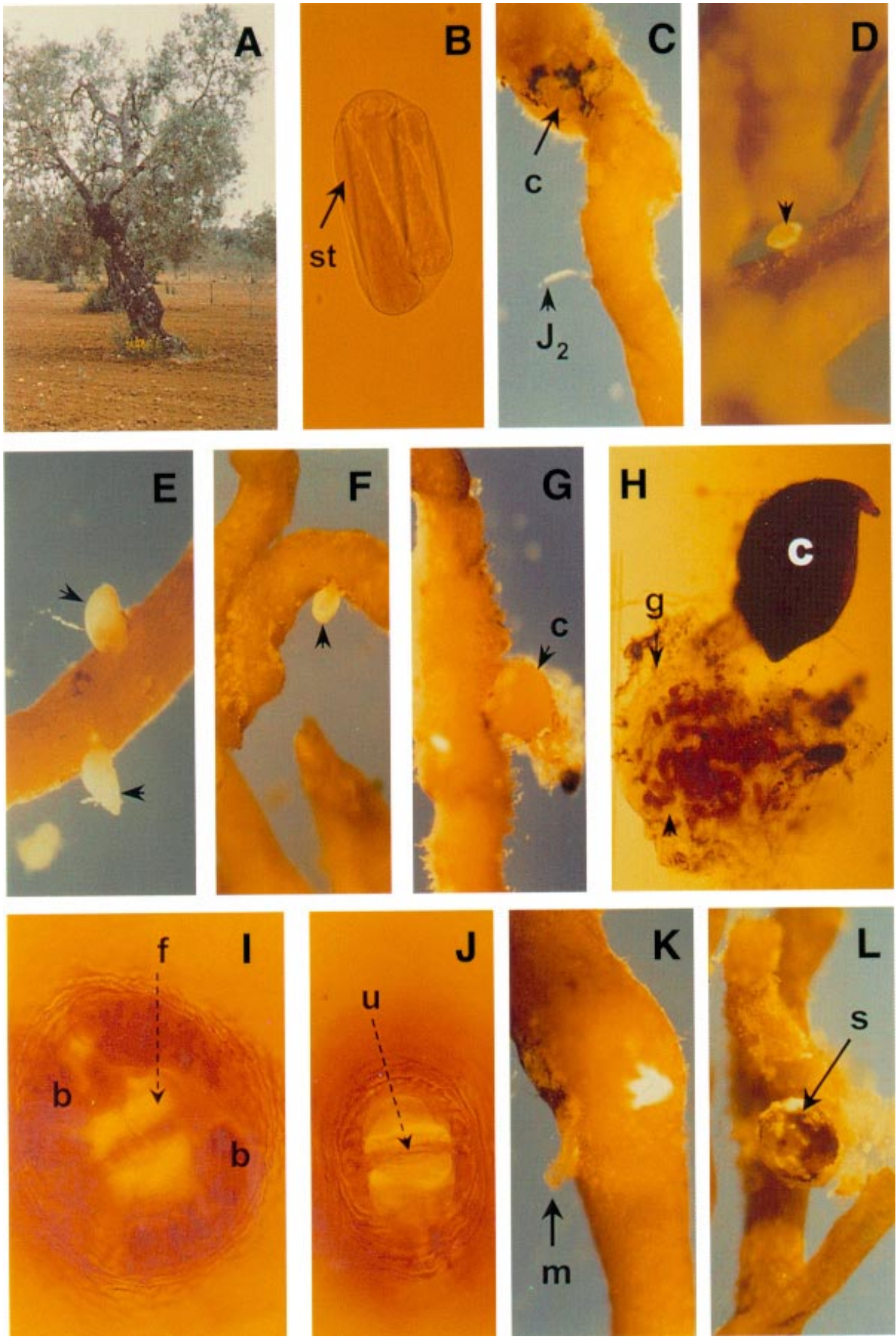

Fig. 1. (A) Parasitism of olive trees cv. Manzanilla by Heterodera mediterranea: An ancient olive infected by a large population of Heterodera mediterranea. (B) Embryonated egg with second-stage juvenile. (C) Partially embedded second-stage juvenile and young cyst infecting olive root. (D-F) Exposed juveniles (arrows) in slightly distorted roots. (G) Mature female showing large gelatinous matrix without eggs. (H) Mature cyst and gelatinous matrix with eggs (arrows). (I-J) Cyst vulval cones showing fenestra, underbridge and bullae. (K) Male within the fourth cuticle stage. (L) Mature cyst covered by a white thin subcrystalline layer. Abbreviations: $\mathrm{b}=$ bullae, $\mathrm{c}=$ cyst, $\mathrm{e}=$ eggs, $\mathrm{f}=$ fenestra, $\mathrm{g}=$ gelatinous matrix, $\mathrm{J}=$ juveniles, $\mathrm{J}_{2}=$ second-stage juvenile, $\mathrm{m}$ $=$ male, $\mathrm{s}=$ subcrystalline layer, $\mathrm{st}=$ stylet, $\mathrm{u}=$ underbridge . 

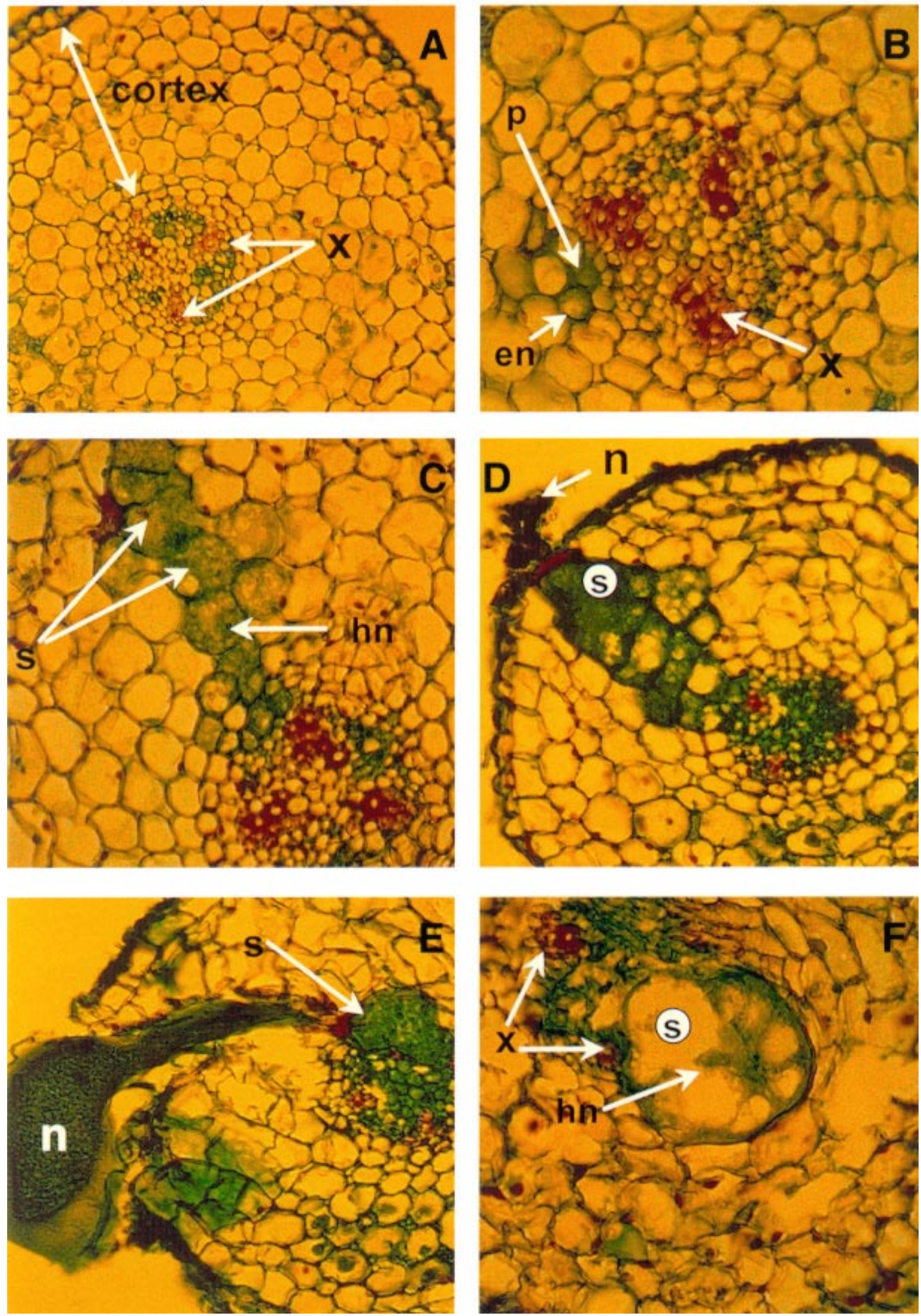

Fig. 2. Histopathology of Heterodera mediterranea-infected roots of adult olive trees cv. Manzanilla. (A) Transverse section of a healthy olive root; (B-F) Transverse sections of olive roots (Manzanilla) infected by H. mediterranea. (B) Distal part of a syncytium involving endodermal and pericycle cells (deeper stained). (C-D) Cortical syncytia involving a number of cells with dense cytoplasm and hypertrophic nuclei. (E) Semi-endoparasitic adult female showing the long neck reaching the stelar syncytium. (F) Magnification of a stelar syncytium showing fused syncytial cells and stelar distortion due to their expansion. Abbreviations: $\mathrm{en}=$ endodermis, $\mathrm{hn}=$ hypertrophic nucleus, $\mathrm{n}=$ nematode, $\mathrm{p}=$ pericycle, $\mathrm{s}=$ syncytium, $\mathrm{x}=\mathrm{xylem}$. 
of $H$. mediterranea in its hosts that differentiates this species from other Heterodera spp.

Histopathology. Histological examination of sectioned healthy (Fig. 2A) and nematode-infected (Fig. 2B to F) olive roots showed that infection by $H$. mediterranea induced cellular alterations in the cortex, endodermis, pericycle, and vascular parenchyma tissues of olive roots. Observations of cross-sections of $H$. mediterra$n e a$-infected roots indicated that the nematode can induce the formation of both cortical and endodermal syncytia. In many cases, the nematode female only penetrated one to three layers of cortical root cells without appearing to reach the stele (Fig. $2 \mathrm{~B}$ to $\mathrm{D})$. In these roots, the nematode established a permanent feeding site in a cortical cell that was fused with adjacent cells forming the syncytium. A syncytium expanded into the cortex by subsequent fusions of 20 to 140 cortical cells. Structurally, cortical syncytia varied in shape and expansion. All syncytia cells were hypertrophic with dense cytoplasm and large nuclei (Fig. 2E to F). In other cases, the nematode female penetrated into the cortex with the anterior elongated body portion and established a permanent feeding site in endodermal tissues (Fig. 2E). These cells fused with adjacent pericyclic cells forming a large stelar syncytium (Fig. $2 \mathrm{E}$ to $\mathrm{F}$ ). Nevertheless, even in these cases, the nematode maintained its semi-endoparasitic habit (Fig. 2E).

Development and parasitic habit of $H$. mediterranea on olive are similar to that of other Heterodera species, except for its semi-endoparasitic habits. Strubell (16) and Steel (15) reported some semi-endoparasitic development of $H$. schachtii on small roots of beet and potato; however, the majority of externally developing nematodes became males. Although no information is available about the parasitic habits of other Heterodera species attacking woody plants, we speculate that the semi-endoparasitic behavior of $H$. mediterranea may be attributed to the woody consistency of olive roots. Vovlas and Inserra
(17) reported the reproduction of $H$. mediterranea on olive under experimental conditions. This report provides the first recorded natural infection on olive and extends the geographical distribution outside the type locality (Torre Canne, southern Italy).

The large nematode population and the anatomical alterations of infected roots suggest that parasitism of olive roots by $H$. mediterranea may contribute to the decline of olive seedlings in new plantations or in olive nurseries. Furthermore, since Verticillium wilt of olive caused by Verticillium dahliae is widespread in the Guadalquivir Valley in southern Spain (2), the possibility exists that these pathogens, when present together in olive fields, may interact synergistically causing more damage and higher severity of Verticillium wilt than would result from infection by either pathogen alone. Synergistic coinfection of $V$. dahliae and plant-parasitic nematodes have been reported in several crops (12), resulting in increased crop damage and yield losses. Therefore, interaction between $H$. mediterranea and $V$. dahliae in olive trees warrants further investigations.

\section{ACKNOWLEDGMENTS}

Research was supported in part by grant OLI96-2131 from Comision Interministerial de Ciencia y Tecnologia (CICYT) of Spain, and Joint Research Program Consejo Superior de Investigaciones Cientificas (CSIC)-Consiglio Nazionale delle Ricerce (CNR). We thank B. Hau, University of Hannover, for his suggestions on the manuscript prior to submission.

\section{LITERATURE CITED}

1. Baldwin, J. G., and Mundo Ocampo, M. 1991. Heteroderinae, cyst- and non-cyst forming nematodes. Pages 275-362 in: Manual of Agricultural Nematology. W. R. Nickle, ed. Marcel Dekker, New York.

2. Blanco-López, M. A., Jiménez-Díaz, R. M., and Caballero, J. M. 1984. Symptomatology, incidence and distribution of Verticillium wilt of olive trees in Andalucía. Phytopathol. Mediterr. 23:1-8.

3. Consejo Oleícola Internacional (COI). 1991. Olive, olive oil, and table olives. (In Spanish). COI, Madrid, Spain.

4. Coolen, W. A. 1979. Methods for the extraction of Meloidogyne spp. and other nematodes from roots and soil. Pages 319-329 in: Rootknot Nematodes (Meloidogyne species) Systematics, Biology and Control. F. Lamberti and C. E. Taylor, eds. Academic Press, London.

5. Filipjev, I. N., and Stekhoven, S. 1941. A Manual of Agricultural Nematology. E. J. Brill, Leiden, Netherlands.

6. Gupta, P., and Edward, J. C. 1973. A new record of cyst-forming nematode (Heterodera chaubattia n. sp.) from the hills of Uttar Pradesh. Curr. Sci. 42:618-620.

7. Hirschmann, H., and Riggs, R. D. 1969. Heterodera betulae n.sp. (Heteroderidae), a cystforming nematode from river birch. J. Nematol. 1:169-179.

8. Hussey, R. S., and Williamson, V. M. 1997. Physiological and molecular aspects of nematode parasitism. Pages 87-108 in: Plan and Nematode Interactions. K. R. Barker, G. A. Pederson, and G. L. Windham, eds. American Society of Agronomy, Madison, WI.

9. Johansen, D. A. 1940. Plant Microtechnique. McGraw-Hill, New York.

10. Krall, E. 1977. Compendium of cyst nematodes in the U.S.S.R. Nematologica 23:311332.

11. Lamberti, F., and Vovlas, N. 1993. Plant parasitic nematodes associated with olive Bull. OEPP/EPPO 23:481-488.

12. Riedel, R. M., Rowe, R. C., and Martin, M. J. 1985. Differential interactions of Pratylenchus crenatus, $P$. penetrans, and $P$. scribneri with Verticillium dahliae in potato early dying disease. Phytopathology 75:419-422.

13. Seinhorst, J. W. 1966. Killing nematodes for taxonomic study with hot f.a. 4:1. Nematologica 12:178.

14. Sher, S. A., and Raski, D. J. 1956. Heterodera fici Kirjanova, 1954 in California. Plant Dis. Rep. 40:700.

15. Steel, A. E. 1971. Orientation and development of Heterodera schachtii on tomato and sugar-beet roots. J. Nematol. 3:424-426.

16. Strubell, A. 1888. Untersuchungen über den Bau und die Entwicklung des Rüben nematoden, Heterodera schachtii Schmidt. Biol. Zool. 1:1-52.

17. Vovlas, N., and Inserra, R. N. 1983. Biology of Heterodera mediterranea. J. Nematol. 15:571-576.

18. Vovlas, N., Inserra, R. N., and Stone, A. R. 1981. Heterodera mediterranea n. sp. (Nematoda: Heteroderidae) on Pistacia lentiscus in southern Italy. Nematologica 27:129-138.

19. Wouts, W. M., and Sher, S. A. 1971. The genera of the subfamily Heteroderinae (Nematoda: Tylenchoidea) with a description of two new genera. J. Nematol. 3:129144. 